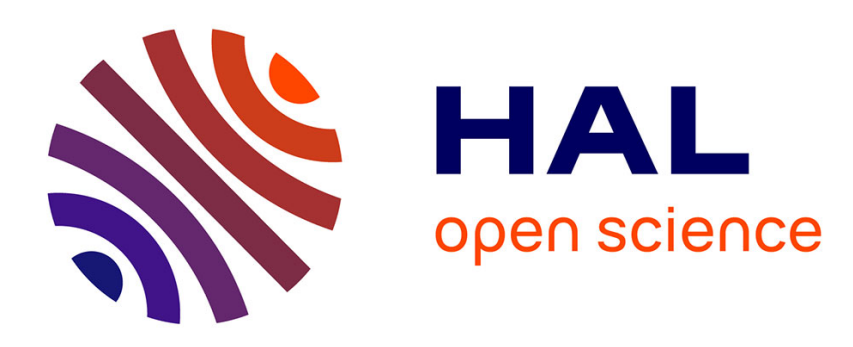

\title{
Family policies : what does the standard endogenous fertility model tell us?
}

Thomas Baudin

\section{To cite this version:}

Thomas Baudin. Family policies: what does the standard endogenous fertility model tell us?. 2008. halshs-00275751

\author{
HAL Id: halshs-00275751 \\ https://shs.hal.science/halshs-00275751
}

Submitted on 25 Apr 2008

HAL is a multi-disciplinary open access archive for the deposit and dissemination of scientific research documents, whether they are published or not. The documents may come from teaching and research institutions in France or abroad, or from public or private research centers.
L'archive ouverte pluridisciplinaire HAL, est destinée au dépôt et à la diffusion de documents scientifiques de niveau recherche, publiés ou non, émanant des établissements d'enseignement et de recherche français ou étrangers, des laboratoires publics ou privés. 


\section{Documents de Travail du Centre d'Economie de la Sorbonne}

C

$\mathrm{Q}$

N

W

0

1

1

$\dot{1}$

n

O

D

a

$\mathrm{p}$

E

1

S

CENTRE NATIONAL

DE LA RECHERCHE

SCENTIFIQUE

Maison des Sciences Économiques, 106-112 boulevard de L'Hôpital, 75647 Paris Cedex 13 http://ces.univ-paris1.fr/cesdp/CES-docs.htm

ISSN : 1955-611X
Endogenous Fertility Model Tell Us?

Thomas BAUDIN

2008.29

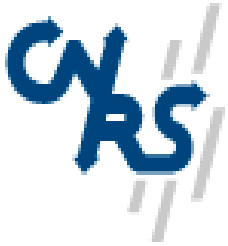




\title{
Family Policies: What Does The Standard Endogenous Fertility Model Tell Us?
}

\author{
Thomas Baudin ${ }^{1}$ \\ Paris School of Economics \\ University of Paris I Panthéon-Sorbonne \\ Centre d'Economie de la Sorbonne \\ 106-112 Boulevard de l'Hôpital \\ 75013 Paris
}

\section{Abstract}

There exists a large consensus in the economic literature and in the economic institutions about the legitimacy of policies subsidizing education. This legitimacy lies in the fact that education is a source of positive externalities. In a standard framework of endogenous fertility, the present paper shows that this result is still valid but that subsidizing education also requires to tax births. Indeed, education subsidies decrease the net cost of children such that parents can exhibit a too high fertility rate. Furthemore, when health is introduced as another source of externalities, the model shows that health expenditures have not always to be subsidized. Indeed, the taxation of births plays the role of an indirect subsidy on health expenditures because it decreases the cost of health relatively to the cost of the quantity of children. When the externalities on education are very high relatively to the positive externalities on health, the indirect subsidy on health can exceed the subsidy that is really needed. Then health expenditures have to be taxed.

JEL Codes: H21, I0, J13, J18

Key Words: Fertility, Education, Family Policy, Mortality, Quality Quantity Trade-off

\footnotetext{
${ }^{1}$ I am grateful to Bertrand Wigniolle, David de la Croix and Victor Hiller for their invaluable help. Discussion with the participants of the EUREQua team's workshop in macroeconomics has been very enlightening.
} 


\section{Introduction}

There exists a large consensus in the economic literature and in the economic institutions about the legitimacy of policies subsidizing education. This legitimacy lies in the fact that education is a source of positive externalities [Hanushek \& Welch (2006)]. The present paper uses a standard framework of endogenous fertility. It shows that this result is still valid but that subsidizing education also requires to tax births. Indeed, education subsidies decrease the net cost of children such that parents can exhibit a too high fertility rate. Following this result, health is introduced as another source of positive externalities because it reduces the child mortality. The model shows that, despite their status of positive externality, health expenditures have not always to be subsidized. Indeed, the taxation of births plays the role of an indirect subsidy on health expenditures because it decreases the cost of health relatively to the cost of the quantity of children. In order to reach the same number of surviving children, parents tend to have less children in better health. When the externalities on education are very high, the tax on births has also to be high. If the positive externalities on health are low, the indirect subsidy can exceed the subsidy that is really needed. Then health expenditures have to be taxed.

The "standard framework" of endogenous fertility comes from the seminal works of Becker et $A l[1973,1976,1988]$. It consists in a model where parents value the number of their offsprings (quantity) as well as their future human capital (quality). They maximize their expected utility subject to a non linear budget constraint ${ }^{2}$. Then a trade-off between quality and quantity takes place. This fundamental contribution of Becker has been followed by major improvements of Galor \& Al [1999, 2002], De la Croix \& Doepke [2003], KalemliOzcan [2003], etc, resulting in a unified framework. Surprisingly there exist very few studies exploring the optimality properties of fertility behaviors in this unified framework.

The question of optimal fertility has been studied in other frameworks. Samuelson [1975], Deardorff [1976] and Michel \& Pestieau [1993] explore the question of the optimal population growth rate in an overlapping generation model with exogenous fertility. A model with endogenous fertility has been proposed by Michel \& Wigniolle [2007] and generalized by

\footnotetext{
${ }^{2}$ This non linearity is fundamental in models of trade-off between quality and quantity. Because quality is provided to each child (with or without equity), its cost crucially depends on the quantity choices. Then the parental budget constraint is no more linear.
} 
Golosov et $A l$ [2007]. Their interest focuses on the Pareto optimality of equilibria. However, they do not deal neither with the quality-quantity trade-off nor with the question of optimal family policies.

Groezen et $A l$ [2003] proposes a model of endogenous fertility and deals with the question of optimal family policies. He argues that, in presence of a Pay As You Go (PAYG) pension system, children are a source of positive externalities because their marginal production will finance the pension system. It implies that the competitive fertility rate is too low, a child allowance has to be implemented ${ }^{3}$. However, if there is no PAYG pension system, the competitive fertility is optimal. Groezen et $\mathrm{Al}$ do not deal with the trade-off between quality and quantity what partly causes this last result.

The present paper is more closely related to contributions of Spiegel [1993] and Balestrino et $A l$ [2000]. They both deal with optimal fiscal schemes in a problem of trade-off between quality and quantity. Their main result is that a taxation of births can constitute an optimal family policy ${ }^{4}$. This result crucially comes from the assumption that the Social Planner tries to reduce inequities ${ }^{5}$. In these models, a tax on births is an efficient instrument to reduce inequities.

In the present paper, a completing approach is proposed. Child mortality is taken into account. Moreover the existence of births taxing is not conditioned neither on the existence of differences between the government objective and the parental preferences nor on a problem of inobservability of behaviors ${ }^{6}$. Indeed, even when the preference of the Social Planner are

\footnotetext{
${ }^{3}$ Loupias \& Wigniolle [2004] show that, in a closed framework, a generalized Allais-Samuelson-Diamond golden rule can be reached only if fertility is subsidized.

${ }^{4}$ Boulding [1964] proposed to implement a market of tradable procreation rights. This idea is explored by De la Croix \& Gosseries [2007]. It finally consists in a system of tax or subsidy on the quantity of children. However they do not explain the reasons why governments are not satisfied with their national fertility. In that sense, the present paper has to be considered as a complement to this literature.

${ }^{5}$ Balestrino et $\mathrm{Al}$ propose a model of optimal taxation where parents are heterogenous. Parental choices are all Pareto efficient. However the government is characterized by a Benthamite function of Social Welfare, then it tries to reduce welfare inequalities between groups of parents. Moreover this government faces a mimicking problem à la Stiglitz (the workforce participations are not observable). Fertility being observable, taxing births can help the government to identify parents that are really poor from mimickers. Another enlightening contribution comes from Cigno and Pettini [2002] who find a similar result without mimicking problems.

Spiegel [1993] proposes a model of trade-off between quality and quantity with a Rawlsian social planner. He shows that a poll tax on births enables to decentralize the social optimum of the economy. However that instrument is a perfect substitute to a tax on the second period consumption.

${ }^{6}$ In the Spiegel's framework, if the government does not value welfare inequalities, no tax on births is
} 
identical to the preferences of parents, a tax on child births is required.

The model's main assumption consists in the existence of externalities in the human capital accumulation ${ }^{7}$. When parents choose their optimal trade-off between quality and quantity, they do not consider that their education investment will improve the overall efficiency of the human capital accumulation process. It implies that, at the competitive equilibrium, they tend to under-invest in education. Then, an optimal economic policy consists in the implementation of a subsidy on education spending. However, the budget constraint of the standard model of trade-off between quality and quantity is not linear. It implies that reducing the costs of quality also reduces the net cost of quantity. In consequence, when it is optimal to subsidize education, it is also optimal to tax births. This central result is robust to the introduction of a natalist bias in the social planner's preferences and to the extension to endogenous child mortality.

The introduction of endogenous child mortality is important in order to discuss some evidence on Family Planning Programs in which the health enhancement is one major issue. In the extended model, higher parental health expenditures reduce child mortality. Furthermore, the average level of health spending has a negative impact on the child mortality. The literature of development economics provides strong evidence that the overall health quality is one of the main determinant of the individual health quality. For example, Dasgupta [1993] shows that 45 percent of all deaths in developing countries can be imputed to infectious and parasitic disease. Private health expenditures help reduce the probability to be affected when an agent is in contact with diseases. Then a higher average level of health expenditures reduces the death probability in all the families. This positive externality implies that private health expenditures are too low at the competitive equilibrium.

In this extended framework, reaching optimality requires, once again, to subside education and to tax births. The taxation of births plays the role of an indirect subsidy on health expenditures. Indeed, it increases the cost of quantity relatively to the cost of health. Parents tend to increase their health expenditures and to decrease the number of births to reach the same number of surviving children. Then, for strong externalities on health

required. In Balestrino et al, even if the social planner dislikes welfare inequalities, the observability of abilities would make the individual indirect utilites observable. Then lump sum transfers would ensure an optimal redistribution of welfare. No tax on births would be necessary.

${ }^{7}$ This is in line with Galor et Al [1999, 2002], De la Croix \& Doepke [2003], Kalemli-Ozcan [2003] etc. 
expenditures, the indirect tax will not be sufficient to reach optimal health expenditures at the competitive equilibrium. So private health expenditures have to be subsidized.

The recommendation to tax births in complement to subsidies for education and health, can be analyzed in the light of some empirical evidence. China and Sub-Saharan African countries, at least, face a problem of overpopulation. They both implement alternative strategies to reduce fertility. China experiments a specific fiscal scheme on births that subsidizes the first birth and strongly taxes the subsequent ones. However, empirical studies like Kanbur \& Zhang [2003] and Fan \& Zhang [2000] show that investments in education and health are insufficient in China. The present paper proposes an alternative fiscal scheme that would reallocate public funds from the first births subsidy to the promotion of education and health, without loss of efficiency in births control.

Sub-Saharan African countries have implemented several family planning programs which strongly promote investments in health and education. However, a recent report of the World Bank [2007] shows that this policy has been inefficient in reducing the net fertility rate in a large majority of these countries. The paper argues that these policies have been inefficient because they did not increase the relative cost of quantity. It shows that more attention should be paid to the implementation of a fiscal scheme that would explicitly sanction births.

The rest of the paper is organized as follows. In section 2, the benchmark model is presented. Its recommendations in term of family policies are discussed. In section 3, endogenous child mortality and public health expenditures are introduced. Section 4 discusses the paper's empirical implications for China and Sub-Saharan Africa. Section 5 concludes.

\section{The Benchmark model}

\subsection{The Competitive Equilibrium}

The model consists in an overlapping generation economy with $L_{t}$ agents who live for two periods: childhood and adulthood. During childhood, an agent receives education from his parent and does not consume. When he becomes adult, he has to choose his consumption level $C_{t}$, the number of his children $N_{t}$ and their education $e_{t}$. For simplicity, families are monoparental. Parents exhibit altruism for their children in the sense that they value their 
future human capital. The parental utility function is noted:

$$
u_{t}=U\left(C_{t}, \xi N_{t}, h_{t+1}\right)
$$

$U(., .,$.$) is strictly increasing and concave in its arguments.$

$N_{t}$ denotes the number of children born in the family and $\left.\xi \in\right] 0,1[$ denotes the fraction of children who survive to age five. The model assumes that parents value the number of surviving children and not the number of children born. It implies that a high child mortality rate is a source of disutility. $\xi$ is exogenous in this section but will be endogenized thereafter. There is no uncertainty about the reproductive success of a family ${ }^{8}$.

Finally, $h_{t+1}$ represents the human capital in $t+1$ of an adult born in $t^{9}$. Following De la Croix \& Doepke [2003], parents finance a schooling time $e_{t}$ and the average human capital of teachers equals the average human capital in the population. There exists an intrafamily transmission of human capital: the human capital of parents $h_{t}$ positively influences the future human capital of children. Because parents do not decide of their own human capital level, the transmission of human capital into the family is an externality. Moreover, the average level of human capital in the population has a positive impact on the children's future human capital. This second externality represents the influence of the efficiency of the school system ( $\overline{h_{t}}$ is the professors' productivity) and the presence of peer effects. Human capital is accumulated through the following process $^{10}$ :

$$
h_{t+1}=f\left(e_{t}, h_{t}, \overline{h_{t}}\right), f_{1}^{\prime}>0, f_{11}^{\prime \prime} \leq 0, f_{2}^{\prime}>0, f_{22}^{\prime \prime}<0, f_{3}^{\prime}>0, f_{33}^{\prime \prime} \leq 0,
$$

The function $f$ is strictly increasing and concave regarding education investments. Note that, following equation (2), $e_{t}$ can be expressed as a function of $h_{t}, \overline{h_{t}}$ and $h_{t+1}$ such that: $e_{t}=e\left(h_{t+1}, h_{t}, \overline{h_{t}}\right)$ and $e_{1}^{\prime}>0, e_{2}^{\prime}<0, e_{3}^{\prime}<0$.

The maximization of utility is subject to the following budget constraint:

$$
C_{t}+\left[\frac{\sigma}{\xi}+\phi\right] w_{t} h_{t} X_{t}+\theta w_{t} \overline{h_{t}} \Omega\left(X_{t}\right) \cdot e_{t}=w_{t} h_{t}
$$

${ }^{8}$ So, contrary to the models of Sah [1991] and Kalemli-Ozcan [2003] that assume uncertainty, parents will not overshoot their number of children to ensure the compliance of their optimal fertility rate. Because a child death is assumed to occur before age five, parents can rapidly ensure the replacement of dead children.

${ }^{9}$ As in Becker [1976], Galor \& Al [1999,2002], De la Croix \& Doepke [2003] and Kalemli Ozcan [2003] the paper assumes that parents directly value the future human capital of their children. They do not value their future well being. In other words, altruism is limited to one generation.

${ }^{10}$ Notice that for all function $\Gamma\left(\alpha_{1}, \alpha_{2}, \ldots ., \alpha_{n}, \ldots.\right), \Gamma_{n}^{\prime}$ represents the partial derivative of $\Gamma$ with regard to $\alpha_{n}$. 
$X_{t} \equiv \xi N_{t}$ represents the number of surviving children at the end of period $t$. Each child born takes a part $\sigma \in] 0,1[$ of its parent's time allocation that is normalized to one. Moreover each surviving child consumes an extra part $\phi$ of this time ${ }^{11}$. Then the quantity cost of a surviving child is greater than the cost of a non surviving child. The total cost of quantity is equal to $\left[\frac{\sigma}{\xi}+\phi\right] w_{t} h_{t} X_{t}$. It includes the ineffective costs engaged for non surviving children. Consequently it negatively depends on the child survival rate.

The cost of one unit of education is not affected by the variations in the child mortality rate. Indeed, no education investment is engaged until a child reaches age five. The total cost of education is concave in $X_{t}$, one unit of education can benefit to more than one child. Then $\theta w_{t} \overline{h_{t}} \Omega\left(X_{t}\right) \cdot e_{t}$ represents the cost of giving $e_{t}$ units of education to $X_{t}$ children with $\Omega^{\prime}\left(X_{t}\right) \geq 0$ and $\Omega^{\prime \prime}\left(X_{t}\right) \leq 0$. If education is a pure public good in the family $\left(\Omega\left(X_{t}\right)=1\right)$, providing $e_{t}$ units of education to one child implies the same cost as providing $e_{t}$ units to $X_{t}$ children. If education is a pure private good in the family $\left(\Omega\left(X_{t}\right)=X_{t}\right)$, one unit of education benefits to only one child. Then the total cost of education equals the unitarian cost of education times the number of surviving children.

The price of the final good is normalized to one. It is produced in quantity $Y_{t}$, following a linear technology:

$$
Y_{t}=A H_{t}
$$

$A$ is a productivity factor and $H_{t}$ is the total amount of human capital in the workforce. At the labor market's equilibrium, $H_{t}$ is:

$$
H_{t}=\left[1-\left(\frac{\sigma}{\xi}+\phi\right) X_{t}-\theta e_{t} \Omega\left(X_{t}\right)\right] h_{t} L_{t}
$$

Note that, ex-post, at the equilibrium of the labor market, $\overline{h_{t}}=h_{t}$. The workforce participation of a parent consists in his remaining time after childbearing and professors do not participate to the production of the final good. Furthermore, as the labor market is competitive, the wage equals the workers' marginal productivity:

$$
w_{t}=A
$$

A parent born in $t-1$ determines his optimal demands $\left(C_{t}^{*}, X_{t}^{*}, h_{t+1}^{*}\right)$ by maximizing $u_{t}=$

\footnotetext{
${ }^{11}$ Note that $\frac{\sigma}{\xi}+\phi<1 . \theta>0$ is a scalar that allows the relative education costs to vary.
} 
$U\left(C_{t}, X_{t}, h_{t+1}\right)$ with respect to $C_{t}, X_{t}$ and $h_{t+1}{ }^{12}$ subject to (2) and (3). This problem can be solved by maximizing the objective function $V_{t}\left(X_{t}, h_{t+1}\right)$ with respect to $X_{t}$ and $h_{t+1}$ :

$$
V_{t}\left(X_{t}, h_{t+1}\right) \equiv U\left(w_{t} h_{t}-\left[\frac{\sigma}{\xi}+\phi\right] w_{t} h_{t} X_{t}-\theta w_{t} \overline{h_{t}} \Omega\left(X_{t}\right) e\left(h_{t+1}, h_{t}, \overline{h_{t}}\right), X_{t}, h_{t+1}\right)
$$

To ensure the global concavity of the problem, the Hessian Matrix of the problem is assumed to be positive semi-definite.

The competitive equilibrium is described by the set $\left\{C_{t}^{*}, X_{t}^{*}, e_{t}^{*}, h_{t}^{*}, \overline{h_{t}^{*}}, h_{t+1}^{*}, H_{t}^{*}, Y_{t}^{*}, w_{t}^{*}\right\}$ satisfying equations $(2),(3),(4),(5),(6)$ and the following First Order Conditions:

$$
\begin{aligned}
U_{X}^{\prime} & =\left(\frac{\sigma}{\xi}+\phi+\theta \Omega^{\prime}\left(X_{t}^{*}\right) e\left(h_{t+1}^{*}, h_{t}^{*}, h_{t}^{*}\right)\right) A h_{t}^{*} U_{C}^{\prime} \\
\frac{U_{h_{t+1}^{\prime}}^{\prime}}{U_{C}^{\prime}} & =\theta A h_{t}^{*} \Omega\left(X_{t}^{*}\right) e_{1}^{\prime}\left(h_{t+1}^{*}, h_{t}^{*}, h_{t}^{*}\right)
\end{aligned}
$$

At the competitive equilibrium, $\overline{h_{t}^{*}}=h_{t}^{*}$, there is no inequality of human capital. The existence of externalities on the human capital accumulation implies that the competitive equilibrium cannot be optimal. The next section derives the social optimum of the economy and compares it to the competitive equilibrium.

\subsection{The Social Optimum}

The presence of externalities makes the private choices on education inefficient. Parents do not consider the positive effect of their educational investments on the overall efficiency of human capital accumulation. Consequently, they naturally tend to under invest in education. Intuitively, the implementation of a subsidy on education should be sufficient to correct this distortion. The equilibrium would be ensured by the existence of a lump sum tax on incomes. However, doing so implicitly assumes that education is a pure public good into the family and that the objective of the Social Planner is the same as the objective of the representative agent.

Defining the Social Planner's objective function is not straightforward. The present paper does not deal with equity objectives. The Social Planner want to maximize the agents' utility. The crucial point lies in his preference for the size of populations.

\footnotetext{
${ }^{12}$ Note that, $h_{t+1}$ depends on the familial human capital, the average human capital and educational choices of parents. As parents know the level of $h_{t}$ and $\overline{h_{t}}$ when they determine $e_{t}$; choosing $e_{t}$ is equivalent to choosing $h_{t+1}$.
} 
One representation of the Social Planner's preferences is usual when fertility is endogenous. In this representation, the Social Planner tries to maximize the utility of the representative agent ${ }^{13} U(C, X, h)$. Doing so implies that he is interested in the well-being of the representative agent without taking care of the size of the population enjoying $U(C, X, h)$. In the present model, the Social Planner takes care of the size of the generations enjoying $U(C, X, h)$. To do so, a natalist bias is introduced in his preferences. The Social Welfare function, at the steady state, is then:

$$
S U=f(X) U(C, X, h)
$$

This formulation is a generalization of the usual case where $f(X)=1$. $f(X)$ represents the "Social Planner's Natalist Bias". For a given $X$, a higher value of $f(X)$ means that the Social planner exhibits a higher natalist bias. In other words, ceteris paribus, he prefers larger generations. $f(X)$ is assumed to be strictly increasing and concave in $X^{14} \cdot f^{\prime}(X)>0$ simply means that distributing $\bar{U}$ to one agent is less valuable than distributing $\bar{U}$ to $X>1$ agents. $f^{\prime \prime}(X)<0$ ensures the existence of the trade-off between the utility distributed to the representative agent and the size of the generation enjoying it.

Then, the Social Planner maximizes (10) subject to the following resource constraint:

$$
C=\left[1-\left(\frac{\sigma}{\xi}+\phi\right) X-\theta \Omega(X) e\right] A h
$$

The optimal steady state is described by the set $\{\widehat{C}, \widehat{X}, \widehat{h}\}$ satisfying equation (11) and the following First Order Conditions:

$$
\begin{aligned}
U_{X}^{\prime} & =-\frac{f^{\prime}(\widehat{X})}{f(\widehat{X})} U(\widehat{C}, \widehat{X}, \widehat{h})+\left(\frac{\sigma}{\xi}+\phi+\theta \Omega^{\prime}(\widehat{X}) e(\widehat{h}, \widehat{h}, \widehat{h})\right) A \widehat{h} U_{C}^{\prime} \\
\frac{U_{h_{t+1}}^{\prime}}{U_{C}^{\prime}} & =A\left(\widehat{X}\left[\frac{\sigma}{\xi}+\phi\right]+\theta \Omega(\widehat{X})\left[e(\widehat{h}, \widehat{h}, \widehat{h})+\widehat{h}\left(\widehat{e}_{1}+\widehat{e}_{2}^{\prime}+\widehat{e}_{3}^{\prime}\right)\right]-1\right)
\end{aligned}
$$

Obviously, at the optimal steady state, all the existing externalities are taken into account.

\footnotetext{
${ }^{13}$ See Groezen et $A l$ [2003], Wigniolle \& Loupias [2004], Zhang [2003], Zhang \& Zhang [2007], etc. This formulation can also be included in the A-Efficiency problems from Golosov et $A l$ [2007].

${ }^{14}$ Let $H(W)$ be the Hessian matrix of the social planner's objective function $W_{t}=$ $f\left(X_{t}\right) U\left(\left[1-\left(\sigma N_{t}-\phi+\theta e\left[h_{t+1}, h_{t}, \overline{h_{t}}\right]\right) X\right] A h, X_{t}, h_{t+1}\right)$. To ensure global concavity $H(W)$ is assumed to be positive semi-definite
} 
In this economy, externalities concern the accumulation of human capital. When parents invest in education, they improve the future human capital of their children, such that, in turn, they improve both the future average level of human capital in the economy and their dynasty's level of human capital. However parents do not take into account that positive impact on the future efficiency of the accumulation process. It implies that they tend to underinvest in education.

Furthermore the preferences of parents differ from the preferences of the social planner. Parents are not concerned with pro-natalism. Consequently they could make too few children. However the externalities on education increase their fertility rate because quality and quantity are substitutes. The competitive equilibrium can then be characterized by over or under fertility. The implementation of an economic policy is required.

\subsection{The Optimal Family Policy}

In order to decentralize the social optimum, the government has to implement a public policy which makes the competitive steady state ${ }^{15}$ converges to the optimal one. An optimal policy makes the set $\left\{C^{*}, X^{*}, h^{*}\right\}$ identical to the set $\{\widehat{C}, \widehat{X}, \widehat{h}\}$. The following sub-sections discuss the optimal family policies in the general case $(\Omega(X) \neq 1)$ and in the specific case where education is a pure public good inside the family $(\Omega(X)=1)$.

To summary, education choices are not optimal because there exist an externality on education investments. A subsidy for education spending has to be implemented to correct this externality. Fertility choices are not optimal for two reasons. First, the Social Planner does not exhibit the same preferences for quantity as individuals. Second, when the cost structure is not linear $(\Omega(X) \neq 1)$, the implementation of the education subsidy decreases the total quantity costs. A tax or a subsidy on births has to be implemented. Obviously, such a family policy will not be required in the specific case where the Social Planner exhibits no Fertility Bias $(f(X)=1)$ and education is a pure public good in the family $(\Omega(X)=1)$.

\footnotetext{
${ }^{15}$ At the competitive steady state, $h_{t+1}^{*}=h_{t}^{*}=\overline{h_{t}^{*}}$.
} 


\subsubsection{Optimal Family Policy in the general case}

Proposition 1 Whatever the intensity of the Social Planner's natalist bias, a policy of education subsidies is optimal when it is completed with a family policy that can be either a tax or a subsidy on births. The government budget constraint has to be balanced by the implementation of a lump sum tax on each family.

Proof. The economic policy described in proposition 1 leads to the following competitive steady state:

$$
\begin{aligned}
U_{X}^{\prime} & =\left(\frac{\sigma+\Lambda}{\xi}+\phi+\Omega^{\prime}\left(X^{*}\right) \theta(1-\kappa) e\left(h^{*}, h^{*}, h^{*}\right)\right) A h^{*} U_{C}^{\prime} \\
\frac{U_{h}^{\prime}}{U_{C}^{\prime}} & =\theta A h^{*} \Omega\left(X^{*}\right)(1-\kappa) e_{1}^{\prime}\left(h^{*}, h^{*}, h^{*}\right) \\
C^{*} & =\left[1-\left(\frac{\sigma+\Lambda}{\xi}+\phi\right) X^{*}+\theta(1-\kappa) e\left(h^{*}, h^{*}, h^{*}\right) \Omega\left(X^{*}\right)\right] A h^{*}-t \\
t & =\kappa \theta e\left(h^{*}, h^{*}, h^{*}\right) \Omega\left(X^{*}\right) A h^{*}-\frac{\Lambda}{\xi} X^{*} A h^{*}
\end{aligned}
$$

$\Lambda>0($ resp $\Lambda<0)$ represents a tax (resp a subsidy) on each child birth. $\kappa>0$ (resp $\kappa<0$ ) denotes a subsidy (resp a tax) on educational investments. When parents invest in one unit of education, they only pay a part $1-\kappa$ of this investment. $t$ is the lump sum tax making the government budget constraint balanced. Equation (17) represents the government budget constraint; equations (14) and (15) are just the expression of equations (8) and (9) when the economic policy is implemented.

Observing systems $\{11,12,13\}$ and $\{14,15,16,17\}$, any policy making the sub-systems $\{14,15\}$ and $\{12,13\}$ identical, decentralizes the social optimum. Indeed, (16) and (17) imply that (11) is satisfied. It follows that ${ }^{16}$ :

$$
\begin{aligned}
& \widehat{\kappa}=\frac{1-\widehat{X}\left[\frac{\sigma}{\xi}+\phi\right]-\theta \Omega(\widehat{X})\left[\widehat{e}+h\left(\widehat{e}_{2}^{\prime}+\widehat{e}_{3}^{\prime}\right)\right]}{\theta \Omega(\widehat{X}) \widehat{h} \hat{e}_{1}^{\prime}} \\
& \frac{\widehat{\Lambda}}{\xi}=-\frac{f^{\prime}(\widehat{X})}{f(\widehat{X})} \frac{\widehat{U}}{A \hat{h} \widehat{U}_{C}^{\prime}}+\frac{\Omega^{\prime}(\widehat{X}) \widehat{e}}{\Omega(\widehat{X}) \widehat{h} \widehat{e}_{1}^{\prime}}\left(1-\widehat{X}\left[\frac{\sigma}{\xi}+\phi\right]-\theta \Omega(\widehat{X})\left[\widehat{e}+\widehat{h}\left(\widehat{e}_{2}^{\prime}+\widehat{e}_{3}^{\prime}\right)\right]\right) \\
& \widehat{t}=\varepsilon_{\widehat{X}}^{f(\widehat{X})} \frac{\widehat{U}}{\widehat{U}_{C}^{\prime}}+\frac{A \widehat{e}}{\widehat{e}_{1}^{\prime}}\left(1-\varepsilon_{\widehat{X}}^{\Omega(\widehat{X})}\right)\left(1-\widehat{X}\left[\frac{\sigma}{\xi}+\phi\right]-\theta \Omega(\widehat{X})\left[\widehat{e}+\widehat{h}\left(\widehat{e}_{2}^{\prime}+\widehat{e}_{3}^{\prime}\right)\right]\right)
\end{aligned}
$$

${ }^{16}$ Notice that $U \equiv U(\widehat{C}, \widehat{X}, \widehat{h})$ and $\widehat{e}=e(\widehat{h}, \widehat{h}, \widehat{h})$. 
By $(11), \widehat{\kappa}$ can be expressed as:

$$
\widehat{\kappa}=\frac{\frac{\widehat{C}}{A \widehat{h}}-\theta \Omega(\widehat{X}) h\left(\widehat{e}_{2}^{\prime}+\widehat{e}_{3}^{\prime}\right)}{\theta \Omega(\widehat{X}) \widehat{h} \widehat{e}_{1}^{\prime}}
$$

$\widehat{e}_{2}^{\prime}+\widehat{e}_{3}^{\prime}<0$ implies that $\widehat{\kappa}$ is always positive. The optimal education policy is always a subsidy. $f^{\prime}(\widehat{X})$ and $\Omega^{\prime}(\widehat{X})$ being different from zero, $\widehat{\Lambda}$ and $\widehat{t}$ are also different from zero: a family policy and a lump sum tax are effectively required to reach the optimal steady state.

An education subsidy has to be implemented because the human capital accumulation process is affected by externalities. Parents under estimate the returns of education, then they tend to under-invest in their children's human capital. The optimal fiscal policy on births has two determinants. The first one is the Social Planner's natalist bias. If the Social Planner exhibits a strong preference for large populations, the competitive fertility rate is too small. The second determinant of the optimal policy on births is the optimal education policy itself. The non linearity of the parental budget constraint implies that a reduction in the education costs reduces the total net cost of a surviving child. Then parents tend to make more children. One main issue of that paper is to determine the condition where births have to be taxed ${ }^{17}$.

Proposition 2 For low intensities of the Social Planner's natalist bias such that $0<\varepsilon_{\widehat{X}}^{f(\widehat{X})}<$ $\widetilde{\varepsilon}$, to tax births is an optimal family policy.

Proof. After some calculus on (19), the following condition can be obtained:

$$
\frac{\widehat{\Lambda}}{\xi}>0 \Leftrightarrow \varepsilon_{X}^{f(X)}<\frac{\varepsilon_{C}^{U(C, X, h)} \cdot \varepsilon_{X}^{\Omega(X)}}{\varepsilon_{h_{t+1}}^{e}}\left(1-\frac{\theta \Omega(X) A h e}{C}\left[\varepsilon_{h_{t}}^{e}+\varepsilon \frac{e}{h_{t}}\right]\right) \equiv \widetilde{\varepsilon}
$$

$\varepsilon_{h_{t}}^{e}+\varepsilon_{h_{t}}^{e}<0$ implies that $\widetilde{\varepsilon}>0$.

The value of $\widetilde{\varepsilon}$ is determined by the model's key variables. When the elasticity of utility to consumption $\left(\varepsilon_{C}^{U(C, X, h)}\right)$ is high, parents tend to consume a great part of their income. They

\footnotetext{
${ }^{17}$ Let $\varepsilon_{m}^{p(m)}$ denotes the elasticity of $p(m)$ with regard to $m$. So $\varepsilon_{m}^{p(m)} \equiv \frac{\frac{\partial p(m)}{\partial m} \cdot m}{p(m)} \forall m$ and $\forall p(\cdot)$ being twice differentiable.
} 
tend to have few children. Therefore, all other things being equal, the competitive fertility rate is low and the tax level has not to be very high and could even become a subsidy ${ }^{18}$.

When the private returns of investment in human capital are high (low values of $\varepsilon_{h_{t+1}}^{e}$ ) relatively to its social returns $\left(\varepsilon_{h_{t+1}}^{e}-\left[\varepsilon_{h_{t}}^{e}+\varepsilon_{\overline{h_{t}}}^{e}\right]\right)$, the tax will be low. Indeed, this implies that the distortions on education choices are low, so the educational subvention is low. Because the tax on births correct the distortion provoked by the subsidy on education, its level will be low too.

Corollary 3 When there is no difference between the preferences of the Social Planner and the preferences of individuals $\left(\varepsilon_{X}^{f(X)}=0\right)$, the optimal family policy is necessary a tax on births.

Proof. If $\varepsilon_{X}^{f(X)}=0,(21)$ is always satisfied.

Indeed, when the Social Planner has the same preferences as parents, initially, at the competitive steady state, fertility behaviors are optimal. However, when the social planner implements subsidies on education investments, the cost of quantity also decreases. Then over fertility appears and a tax on births has to be implemented.

This result is crucial for models of trade-off between quality and quantity. It implies that leading generous education policies could require restrictive family policies when education is not a pure public good in the family. The following sub-section explores the precedent optimal fiscal scheme in the specific case where education is a pure public good inside the family.

\subsubsection{Optimal Family Policy when education is a pure public good in the family}

In this case, the cost of providing $e_{t}$ units of education to one child is the same as the cost of providing $e_{t}$ units of education to an infinite number of children. It implies that the precedent results are sensibly modified.

Proposition 4 When education is a pure public good in the family, taxing births is never necessary to decentralize the optimal steady state. Furthermore, if the Social Planner does not exhibit a Natalist Bias, no family policy is required to reach the optimal steady state.

\footnotetext{
${ }^{18}$ If the elasticity of utility to consumption is considered as an indicator of parental individualism, a society with a strong individualism will need to subside births to reach the social optimum.
} 
Proof. If $\Omega^{\prime}(X)=0$, the fiscal scheme decentralizing the optimal steady state is the expression of system $\{18,19,20\}$ with $\Omega(X)=1$ and $\Omega^{\prime}(X)=0$ :

$$
\begin{aligned}
\widehat{\kappa} & =\frac{1-\widehat{X}\left[\frac{\sigma}{\xi}+\phi\right]-\theta\left[\widehat{e}+h\left(\widehat{e}_{2}^{\prime}+\widehat{e}_{3}^{\prime}\right)\right]}{\theta \widehat{h} \widehat{e}_{1}^{\prime}} \\
\frac{\widehat{\Lambda}}{\xi} & =-\frac{f^{\prime}(\widehat{X})}{f(\widehat{X})} \frac{U}{A \widehat{h} U_{C}^{\prime}} \\
\widehat{t} & =\varepsilon_{\widehat{X}}^{f(\widehat{X})} \frac{U}{U_{C}^{\prime}}+\frac{A \widehat{e}}{\widehat{e}_{1}^{\prime}}\left(1-\widehat{X}\left[\frac{\sigma}{\xi}+\phi\right]-\theta \Omega(\widehat{X})\left[\widehat{e}+\widehat{h}\left(\widehat{e}_{2}+\widehat{e}_{3}^{\prime}\right)\right]\right)
\end{aligned}
$$

By the proof of proposition 3, $\widehat{\kappa}>0$. Education has to be subsidized. It is straightforward that $\widehat{\Lambda} \leq 0$. When $f^{\prime}(X)=0$, it follows from $(23)$ that $\widehat{\Lambda}=0, \widehat{\kappa}>0$ and $\widehat{t}>0$.

The fundamental results of the model has not really changed. Equation (19) is still satisfied, however the education policy does not distort fertility behaviors anymore. Indeed, as education is a pure public good in the family, the total costs of education are not influenced by the number of children that enjoy the education investment. So only the distance between the Social Planner's preferences and the household's preferences can make non optimal the fertility behaviors. Without this bias, competitive fertility choices are optimal and no family policy is required.

As a first major result, in a standard model of trade-off between quality and quantity, a family policy is always required to reach the optimal steady state if education is not a pure public good. In other words, without the implementation of a tax or a subsidy on births, an education policy is not completely effective. This result provides some incentives to modify the nature of family planning programs which do not implement taxes or subsidies on births. However, these programs do promote health expenditures. In the following section, the model is extended to the existence of private health expenditures. The need to tax births will not be canceled by the introduction of health expenditures.

\section{Optimal family policy with health expenditures}

The children survival probability is now endogenous. Parents can engage health expenditures

in order to reduce their children's death probability. In line with Shakraborty [2004], the 
child survival probability $\xi_{t}$ is now:

$$
\xi_{t} \equiv \xi\left(s_{t}, \overline{s_{t}}\right)
$$

The parental expenditures on health have a strictly positive and concave influence on the children's survival probability, so $\xi_{1}^{\prime} \equiv \frac{\delta \xi\left(s_{t}, \overline{s_{t}}\right)}{\delta s_{t}}>0$ and $\xi_{11}^{\prime \prime} \equiv \frac{\delta^{2} \xi\left(s_{t}, \overline{s_{t}}\right)}{\delta s_{t}{ }^{2}}<0$. These expenditures represent the health care provided by parents to children. Parental health care covers a large set of expenditures like hygiene, sanitation improvements and efficient nutrition. $\overline{s_{t}}$ denotes the average health expenditures in the economy. In line with Dasgupta [1993], let assume that $\xi_{2}^{\prime} \equiv \frac{\delta \xi\left(s_{t}, \overline{s_{t}}\right)}{\delta \bar{s}_{t}}>0$ and $\xi_{22}^{\prime \prime} \equiv \frac{\delta^{2} \xi\left(s_{t}, \overline{s_{t}}\right)}{\delta \bar{s}_{t}{ }^{2}}<0$.

The introduction of an externality on health expenditures implies that the parental choices on $s_{t}$ will not be efficient at the competitive equilibrium. Intuitively, one can expect that the competitive level of health expenditures will be inferior to its optimal level. However, the existence of educational inefficiency could alter this result because, as previously, it decreases the total cost of quantity.

\subsection{The Competitive Equilibrium}

Parents now have to determine health expenditures for their children. In other words, they choose $X_{t}$ and $s_{t}$. The addition of an externality on health spending implies that private health investments will not be optimal. Then the government introduces a subsidy $r_{t}$ on health expenditures in complement to the previous fiscal system. The government budget constraint is now ${ }^{19}$ :

$$
t_{t}=\kappa_{t} \theta e\left(h_{t+1}, h_{t}, h_{t}\right) X_{t} w_{t} h_{t}-\frac{\Lambda_{t} w_{t} h_{t}}{\xi\left(s_{t}, \overline{s_{t}}\right)} X_{t}+r_{t} s_{t}
$$

When the fiscal scheme is implemented, the familial budget constraint is:

$$
C_{t}+\left(1-r_{t}\right) s_{t}+\left[\frac{\sigma+\Lambda_{t}}{\xi\left(s_{t}, \overline{s_{t}}\right)}+\phi\right] w_{t} h_{t} X_{t}+\left(1-\kappa_{t}\right) \theta w_{t} \overline{h_{t}} X_{t} \cdot e_{t}=w_{t} h_{t}
$$

Now the final good can either be consumed or invested in health. Parents have to maximize the objective function $U\left(C_{t}, X_{t}, h_{t+1}\right)$ with regard to $C_{t}, X_{t}$ and $h_{t+1}$ and with respect to $(27)$. As health expenditures do not enter the objective function, parents determine

\footnotetext{
${ }^{19}$ To simplify the results, let assume $\Omega^{\prime}(X)=1$. Education is a pure private good.
} 
their optimal health expenditures by minimizing $\left(1-r_{t}\right) s_{t}+\frac{\sigma+\Lambda_{t}}{\xi\left(s_{t}, \overline{s_{t}}\right)} w_{t} h_{t} X_{t}$. It follows that, at the competitive steady state:

$$
1-r=\frac{[\sigma+\Lambda] \xi_{1}^{* \prime}}{\left[\xi\left(s^{*}, s^{*}\right)\right]^{2}} X^{*} w h^{*}
$$

Parents equalize the marginal return and the marginal cost of health expenditures $(1-r)$. The marginal benefit of health expenditures $\left(\frac{[\sigma+\Lambda] \xi_{1}^{* \prime}}{\left[\xi\left(s^{*}, s^{*}\right)\right]^{2}} X^{*} w h^{*}\right)$ consists in the reduction of the total cost of quantity ${ }^{20}$. In other words, the equation (28) determines the optimal parental spending on health to have $X_{t}$ surviving children.

The competitive steady state is now described by the set $\left\{C^{*}, X^{*}, s^{*}, e^{*}, h^{*}, \overline{h^{*}}, H^{*}\right.$, $\left.Y^{*}, w^{*}\right\}$ satisfying equations $(5),(6),(27),(28)$ and the following first order conditions with regard to $X$ and $h$ :

$$
\begin{aligned}
\frac{U_{X}^{\prime}}{U_{C}^{\prime}} & =\frac{\left(\sigma+\Lambda+\left[\phi+(1-\kappa) \theta e\left(h^{*}, h^{*}, h^{*}\right)\right] \xi\left(s^{*}, s^{*}\right)\right)}{\xi\left(s^{*}, s^{*}\right)} w h^{*} \\
\frac{U_{h_{t+1}^{\prime}}^{\prime}}{U_{C}^{\prime}} & =(1-\kappa) X^{*} \theta w h^{*} e_{1}^{\prime}\left(h^{*}, h^{*}, h^{*}\right)
\end{aligned}
$$

Following equations (28) and (29), it appears that the taxation of births increases the marginal cost of quantity and increases the marginal benefice of health expenditures.

\subsection{The Social Optimum}

For simplicity, $f(X)=1$ is assumed. The Social Planner maximizes $S U=U(C, X, h)$. He holds a new maximization instrument $s$ and he faces a new resource constraint:

$$
C+s=\left[1-\left(\frac{\sigma}{\xi(s, \bar{s})}+\phi+\theta e\right) X\right] A h
$$

The optimal equilibrium now results from the maximization of the following objective function with regard to $X$ and $h$ :

$$
S U=U\left(\left[1-\left(\frac{\sigma}{\xi(s, \bar{s})}+\phi+\theta e\right) X\right] A h-s, X, h\right)
$$

At the steady state $s=\bar{s}$. The social planner determines the optimal health expenditures by minimizing $\frac{\sigma}{\xi(s, \bar{s})} X A h+s$ with regard to $s$. Doing so, he equalizes the marginal social

\footnotetext{
${ }^{20}$ As mentionned in the Benchmark model, a higher child survival rate decreases the cost of quantity.
} 
cost of health spending (equal to one) to its marginal social cost. Obviously, the marginal social benefit of health spending is higher than the marginal private benefice (calculated in equation (28)). Formally, the optimal decision rule for $s$ is:

$$
1=\frac{\sigma\left[\widehat{\xi}_{1}^{\prime}+\widehat{\xi}_{2}^{\prime}\right]}{[\xi(\widehat{s}, \widehat{s})]^{2}} \widehat{X} A \widehat{h}
$$

Then the Social Optimum is described by the set $\{\widehat{C}, \widehat{X}, \widehat{h}, \widehat{s}\}$ satisfying the equation (31), (32) and the following conditions:

$$
\begin{aligned}
\frac{U_{X}^{\prime}}{U_{C}^{\prime}} & =\frac{(\sigma+[\phi+\theta e(\widehat{h}, \widehat{h}, \widehat{h})] \xi(\widehat{s}, \widehat{s}))}{\xi(\widehat{s}, \widehat{s})} A \widehat{h} \\
\frac{U_{h_{t+1}^{\prime}}^{\prime}}{U_{C}^{\prime}} & =A\left(\widehat{X}\left[\frac{\sigma}{\xi(\widehat{s}, \widehat{s})}+\phi+\theta e(\widehat{h}, \widehat{h}, \widehat{h})+\theta \widehat{h}\left(\widehat{e}_{1}^{\prime}+\widehat{e}_{2}^{\prime}+\widehat{e}_{3}^{\prime}\right)\right]-1\right)
\end{aligned}
$$

\subsection{The Optimal Family Policy}

An optimal policy has to make identical the systems $\{(32),(33),(34)\}$ and $\{(28),(29),(30)\}$. In consequence, the optimal fiscal scheme is:

$$
\begin{aligned}
\widehat{\kappa} & =\frac{1-\widehat{X}\left[\frac{\sigma}{\xi(\widehat{s}, \widehat{s})}+\phi+\theta \widehat{e}+\theta \widehat{h}\left[\widehat{e}_{2}^{\prime}+\widehat{e}_{3}^{\prime}\right]\right]}{\theta \widehat{X} \widehat{h} \widehat{e}_{1}^{\prime}} \\
\frac{\Lambda}{\xi} & =\frac{\widehat{e}}{\widehat{X} h \widehat{e}_{1}^{\prime}}\left(1-\widehat{X}\left[\frac{\sigma}{\xi(\widehat{s}, \widehat{s})}+\phi+\theta \widehat{e}\left(1+\varepsilon_{h}^{e}+\varepsilon \frac{e}{h}\right)\right]\right) \\
\widehat{r} & =1-\frac{\varepsilon_{s}^{\xi(s, \bar{s})}}{\varepsilon_{s}^{\xi(s, s)}+\varepsilon_{\bar{s}}^{\xi(s, \bar{s})}}\left[1+\frac{\widehat{e}\left(1-\widehat{X}\left[\frac{\sigma}{\xi(\widehat{s}, \widehat{s})}+\phi+\theta \widehat{e}\left(1+\varepsilon_{h}^{e}+\varepsilon_{\bar{h}}^{e}\right)\right]\right)}{\widehat{X} h \widehat{e}_{1}^{\prime}}\right] \\
\widehat{t} & =\varepsilon \frac{\xi(s, \bar{s})}{\sigma A \hat{h}} \widehat{\xi(\widehat{s}, \widehat{s})} \widehat{X}-\frac{A h \varepsilon_{s}^{\xi(s, \bar{s})}\left(1-\widehat{X}\left[\frac{\sigma}{\bar{\xi}(\widehat{s}, \widehat{s})}+\phi+\theta \widehat{e}\left(1+\varepsilon_{h}^{e}+\varepsilon_{\bar{h}}^{e}\right)\right]\right)}{\varepsilon_{h}^{e}+1}
\end{aligned}
$$

The optimal values of $\widehat{\kappa}$ and $\widehat{\Lambda}$ are the same as in the previous section (given that the optimal values of $\widehat{C}, \widehat{X}$ and $\widehat{h}$ have changed). It implies that proposition 1 still applies. In other words, whatever the intensity of the Social Planner's natalist bias, a policy of education and health subsidies is optimal when it is completed with a family policy. Here, because the Social Planner exhibits no natalist bias, the optimal family policy is always a tax on births. The government budget constraint still has to be balanced by the implementation of a lump sum tax on each family. 
Proposition 5 When the externality on health expenditures is strong such that $\varepsilon_{\bar{s}}^{\xi(s, \bar{s})}>\bar{\varepsilon}$, the optimal health policy consists in a subsidy.

Proof. It is straightforward to show that parental health expenditures are not optimal at the competitive steady state.

At the competitive steady state (without taxation), (28) and (29) imply $s^{*}=\varepsilon_{s}^{\xi(s, \bar{s})} \sigma A h N$. At the optimal steady state, (32) and (33) imply $\widehat{s}=\left[\varepsilon_{s}^{\xi(s, \bar{s})}+\varepsilon_{\bar{s}}^{\xi(s, \bar{s})}\right] \sigma A h N$. It follows that $s^{*}<\widehat{s}$. However $s^{*}<\widehat{s}$ does not ensure that health expenditures have always to be subsidized. (32) and (33) indicates that the optimal value of health subsidies is:

$$
\widehat{r}=1-\frac{\varepsilon_{s}^{\xi(\widehat{s}, \widehat{s})}}{\varepsilon_{s}^{\xi(\widehat{s}, \widehat{s})}+\varepsilon_{\bar{s}}^{\xi(\widehat{s}, \widehat{s})}}\left(1+\frac{\widehat{\Lambda}}{\xi}\right)
$$

Then, $\widehat{r}$ is positive if the following condition holds:

$$
\varepsilon \bar{s}^{\xi(\widehat{s}, \widehat{s})}>\varepsilon_{s}^{\xi(\widehat{s}, \widehat{s})} \frac{\widehat{\Lambda}}{\xi} \equiv \bar{\varepsilon}
$$

When the externality on $\bar{s}$ is strong, parents tend to largely underinvest in health. Then, health expenditures have to be subsidized. However, for a very high value of the education subsidy relatively to $\varepsilon_{\bar{s}}^{\xi(s, \bar{s})}$, health expenditures have to be taxed. This result comes from the non linearity of the costs structure. Indeed, the existence of an externality on health expenditures implies that parents does not internalize all the returns of their investment in children's health. The comparison of (28) with $\Lambda=r=0$ and (32) indicates that health expenditures at the competitive steady state are lower than at the optimal steady state. However, when education is subsidized, a tax on births has to be implemented. Doing so, the cost of quantity is increased relatively to the cost of health, then parents tend to increase their health expenditures. The tax on births plays the role of an indirect subsidy on health. Finally, the sign of $\widehat{r}$ is determined by the difference between the intensity of the externality on health expenditures and the size of the indirect subsidy. If the externality on health is relatively strong, the indirect subsidy will not be sufficient to reach $\widehat{s}$, then $\widehat{r}$ will be positive. Conversely, if the externality on health is relatively weak, the indirect subsidy exceeds the health subsidy that is really needed. So $\widehat{r}$ will be negative: health expenditures will be taxed. 
To summarize, the present paper provides two results.. First, whenever it is optimal to subsidize education and health, it is optimal to implement a family policy. This family policy always consists in a tax on births because the Social Planner has no natalist bias. Second, when the social returns on health expenditures are sufficiently high, the optimal family planning program of the economy consists in the promotion of education and health financed by the taxation of births and a lump sum tax. This optimal policy has, in fact, two main objectives. The first one is to modify the parental trade-off between quality and quantity. More precisely, the government has to incite parents to transfer a part of their spending on fertility toward education investments. The second objective is to modify the parental trade-off between fertility and health. In order to reach the same number of surviving children, parents are incited to make less children in better health.

\section{Some Empirical Issues At Stake}

Countries which face over-population problems implement active policies to slacken their population growth rate. Two examples are particularly enlightening: China and SubSaharan Africa. If these two regions both face overpopulation problems, their family policies have been sensibly different. In the light of the theoretical fiscal scheme proposed in this paper, this section provides a brief reflection on the improvements that could be leaded to current policies experienced in these countries.

A recent report of the World Bank [2007] underlines that 31 of the 35 countries with the highest fertility rates come from Sub-Saharan Africa. For the majority of them, fertility rates have not changed over the last decades and are all greater than six children per women. However the vast majority of these countries have implemented family planning programs in collaboration with international organization like the World Bank.

The World Bank's report [2007] underlines that the main factor of the high fertility rates is the persistent high level of the desired number of children. In other words, the too high fertility rates in Sub-Saharan Africa do not come from the lack of family planning program disposal. It argues that efforts have to be done to reduce the desired fertility. To do so, it recommends to forecast education and to improve the presence of health programs at the local level. However, education indicators are all increasing since the sixties. More recently, 
the net primary school enrollment rate increased from 50 to 70 percent between 1990 and 2006. In the same period, the youth and adult literacy rates increased ${ }^{21}$. This sensible improvement in education rates has not been sufficient to reduce fertility rates.

The present paper does not recommend to increase the amount spent in the family planning programs. It proposes to complement family planning programs with taxes on births helping to finance education and health. Without taxing births, these programs reduce the net cost of the children quantity implying the persistence of a high desired number of children.

Obviously, the Sub-Saharan African population puzzle cannot be reduced to a simple model of fertility. More complex problems of political instability, starvation and HIV pandemy that are well beyond the scope of this paper, have a direct and significant incidence on fertility and education behaviors. It particularly questions the possibility to implement taxes on births in a population that is largely engaged in an informal economy. However, the increase of quantity costs has to be contemplated as an instrument of future family planning programs.

China also implements a family policy to reduce its population growth rate. However, its strategy differs from the strategy of family planning programs in Sub-Saharan Africa. Since 1980, China implements a One-Child policy which strongly constraints families' fertility. It consists in a system which provides large subsidies for the first birth and imposes very large taxes on the subsequent births. If parents decide to have a second child without being allowed to do so, they lose a large part of their retirement pension, the integrality of their child care helps and other social advantages. Furthermore, some physical sanctions have been implemented in rural areas. This fiscal scheme is relatively different from the one proposed in this paper. The Chinese policy does not tax all the births at the same rate. The first birth is subsidized whereas the subsequent births are largely taxed. The high level of the tax on subsequent births is a very efficient incentive to make only one child. Then the large majority of families are subsidized to reach the target of one child per family. It implies that the Chinese One-Child Policy is a very costly family policy. It cannot finance education and health policies. Then, nothing ensures that the relative costs of education and health

\footnotetext{
${ }^{21}$ In Sub-Saharan Africa, the youth litteracy rate was $64 \%$ in 1990 and $73 \%$ in 2006 . The adult litteracy rate was $54 \%$ in 1990 and $61 \%$ in 2006. See appendix 1 for a more complete description.
} 
reach their optimal value. Indeed, a large literature underlines the insufficiency of public expenditures on health and education in Chinese rural areas where the large majority of the population is concentrated (for example, see Kanbur \& Zhang [2003] and Fan \& Zhang [2000]).

The results of the paper indicate that some marginal changes in the One-Child policy could improve the overall efficiency of the Chinese family planning policy. It proposes to tax all births such that the family policy does not imply effective costs. The amount saved by the Chinese government could be invested in more ambitious education and health policies reducing the large inequalities existing between urban and rural areas. Theoretically, this system would not increase the overall cost of the Chinese family planning program and would lead to the same fertility rates. However, it would increase health and education investments.

\section{Conclusion}

The present paper analyses optimal family policies in the standard model of trade-off between quality and quantity. Given the non linearity of the parental budget constraint, to subsidize education and health will be optimal if and only if a tax (or a subsidy) on births is also implemented. Indeed, a subsidy on education reduces both the cost of education investment and the total cost of fertility. This result still applies when the Social Planner does not suffer from a Natalist bias. Obviously, the model concludes that taxing births without financing education and health is not optimal either.

Finally, the fiscal scheme proposed in this model is quite simple: education and health expenditures are promoted by the taxation of births and lump sum transfers. The implementation of this scheme could improve the overall efficiency of actual family policies implemented in China and Sub-Saharan Africa. The main objective of the present investigation was to explore the family policy recommendations of the standard endogenous fertility model. As a natural extension of this work, future research should integrate countries' specificities to make quantitative propositions of economic policy. 


\section{References}

[1] Balestrino A., Cigno A. \& Pettini A. [2000] "Endogenous Fertility and the Design of Family Taxation" International Tax and Public Finance, Springer, vol. 9(2), 175-193

[2] Becker G.S \& Barro R.J., [1988]. "A Reformulation of the Economic Theory of Fertility," The Quarterly Journal of Economics, MIT Press, vol. 103(1), pages 1-25, February

[3] Becker G.S. \& Lewis H.G. [1973] "On the Interaction Between the Quantity and Quality of Children" The Journal of Political Economy, vol. 81(2) Part 2 New Economic Approach to Fertility, p 279-288

[4] Becker G.S. \& Tomes N. [1976] "Child Endowments and the Quantity and Quality of Children" The Journal of Political Economy, vol. 84 (4) Part 2, Essays in Labor Economics in Honor of H.G. Lewis, p 143-162

[5] Boulding K. [1964]. "The Meaning of the Twentieth Century". London: George Allen and Unwin Ltd.

[6] Chakraborty S. [2004] "Endogenous Lifetime and Economic Growth", Journal of Economic Theory, vol.ume 116(1), p 119-137

[7] Cigno A. \& Pettini A. [2002] "Taxing family size and subsidizing child-specific commodities?", Journal of Public Economics, vol. 84(1), p 75-90

[8] Dasgupta [1993] "An Inquiry Into Well-Being and Redistribution", Oxford University Press, New-York

[9] Deardorff A.V. [1976] "The Optimum Growth Rate for Population: Comment", International Economic Review, vol. 17(2), p 510-515.

[10] De La Croix D. \& Doepke M. [2003] "Inequality and Growth: Why Differential Fertility Matters?" The American Economic Review, American Economic Association, vol. 93(4), p 1091-1113 
[11] De La Croix D. \& Gosseries A. [2007] "Procreation, Migration, and Tradable Quotas, in Population Aging, Intergenerational Transfers and the Macroeconomy", in R. Clark, A.Mason and N. Ogawa eds, Edward Elgar Publishing, p 227-249

[12] Fan S. \& Zhang X. [2000] "Public Investment And Regional Inequality In Rural China", EPTD Discussion Paper $n^{\circ} 71$

[13] Galor O. and Moav O. [2002]. "Natural selection and the origin of economic growth", Quarterly Journal of Economics, vol. 117, p 1133-1192

[14] Galor O. and Weil D.N [1999]. "From Malthusian stagnation to modern growth", American Economic Review, vol. 89, p 150-154.

[15] Golosov M., Jones L.E. \& Tertilt M [2007] "Efficiency with Endogenous Population Growth," Econometrica, Econometric Society, vol. 75(4), p 1039-1071

[16] Groezen B.V., Leers T. and Meijdam L. [2003] "Social security and endogenous fertility: pensions and child allowances as siamese twins", Journal of Public Economics, vol. $87(2)$, p 233-251

[17] Hanusheck E.A. \& Welch F. [2006] "Preface to the Handbook of the Economics of Education" in Handbook of the Economis of Education, Hanusheck E.A. \& Welch F. eds, p 21-22

[18] Kalemli-Ozcan S. [2003] "A stochastic Model of Mortality, Fertility and Human Capital Investment", Journal of Development Economics, vol. 70(1), p 103-118

[19] Kanbur R. \& Zhang X. [2005], "Spatial Inequality in Education and Health Care in China", China Economic Review, vol. 16(2), p 189-204

[20] Loupias C. \& Wigniolle B. [2004] "Régime de retraite et chute de natalité : évolution des moeurs ou arbitrage micro-économique?", Annales d'Economie et de Statistiques, vol. 73, p 63-99

[21] Michel P. \& Pestieau P. [1993] "Croissance optimale avec population fluctuante", Revue économique, vol. 44(3), p 615-624. 
[22] Michel P. \& Wigniolle B. [2007] "On Efficient Child Making", Economic Theory, Springer, vol. 31(2), p 307-326

[23] Samuelson P.A. [1975] "The Optimum Growth Rate for Population", International Economic Review, 531-538

[24] Sah R.K. [1991] "The Effect of Child Mortality Changes on Fertility Choice and Parental Welfare", The Journal of Political Economy, vol. 99(3), p 582-606

[25] Spiegel [1993] "Rawlsian optimal population size", Journal of Population Economics, vol.3, p 363-373.

[26] World Bank [2007] "Population Issues in the 21st century: the role of the World Bank" Health, Nutrition and Population Discussion Paper

[27] Zhang J [2003] "Optimal debt, endogenous fertility, and human capital externalities in a model with altruistic bequests", Journal of Public Economics, vol.ume 87(7-8), p $1825-1835$

[28] Zhang J. \& Zhang J. [2007] "Optimal social security in a dynastic model with investment externalities and endogenous fertility", Journal of Economic Dynamics and Control, vol. 31(11), p 3545-3567 


\section{Appendix}

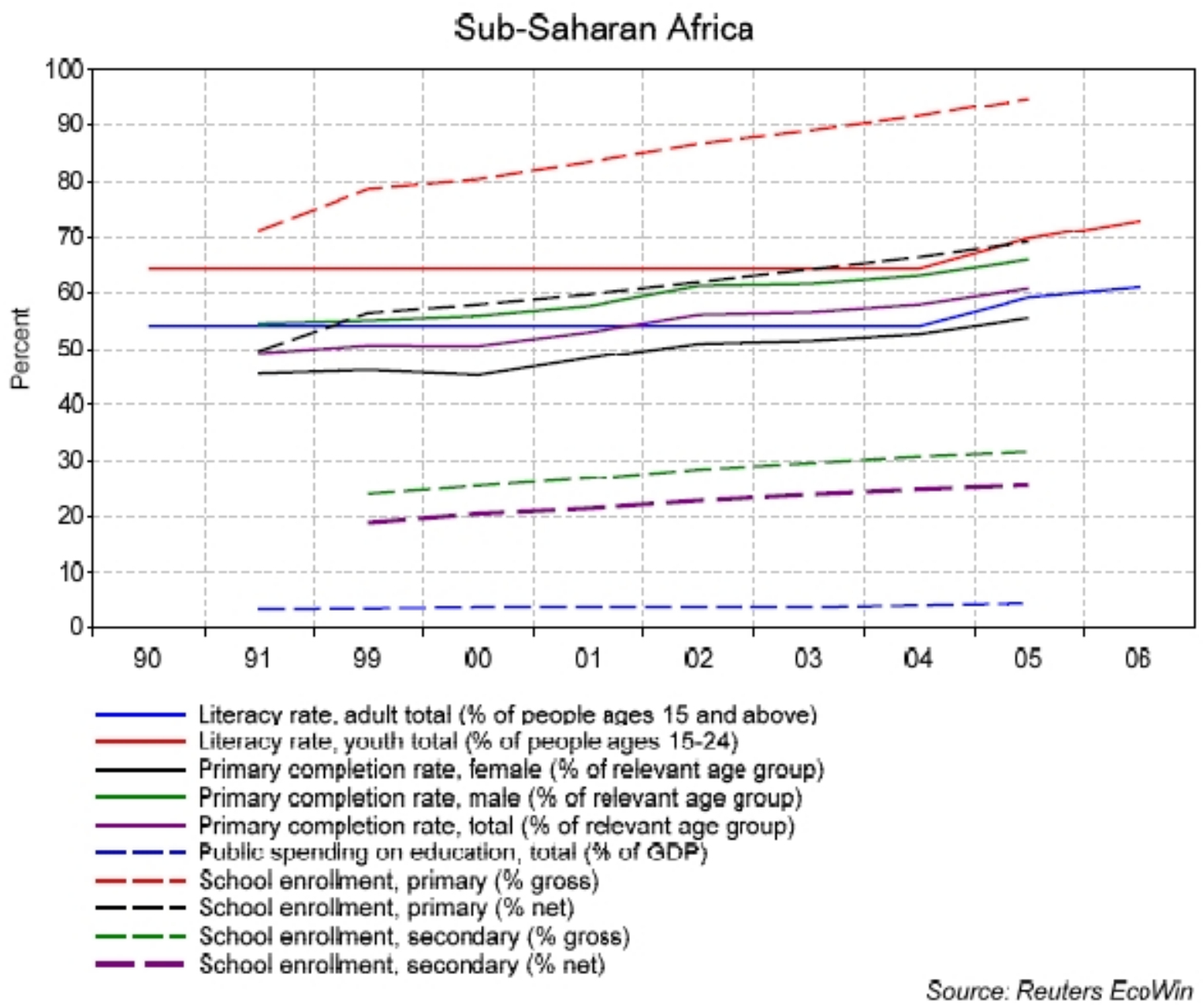

Education in Sub-Saharan AfricaSince 1990 